The work of Bissantz

\begin{tabular}{|l|l|l|}
\hline & ER & TK \\
\hline Max Sim & 1 & 0.92 \\
\hline & & \\
\hline Mean Sim & 0.57 & 0.71 \\
\hline
\end{tabular}

Table 1: Similarities between the query used in the ROCS study and the actives for the Bissantz study.

The work of Evers

\begin{tabular}{|l|l|l|l|c|}
\hline & 5HT2A & A1A & D2 & M1 \\
\hline Max Sim & 0.80 & 0.85 & 0.83 & 0.61 \\
\hline Mean Sim & 0.52 & 0.60 & & \\
\hline & & & 0.56 & 0.45 \\
\hline
\end{tabular}

Table 2: Similarities between the query used in the ROCS study and the actives for the Evers study.

The work of Cummings

\begin{tabular}{|l|l|l|l|}
\hline & PTP-1B & Thrombin & HIV-PR \\
\hline Max Sim & 1.0 & 0.98 & 1.0 \\
\hline & & & \\
\hline Mean Sim & 0.51 & 0.57 & 0.63 \\
\hline
\end{tabular}

Table 3: Similarities between the query used in the ROCS study and the actives for the Cummings study. 
The work of Miteva

\begin{tabular}{|l|l|l|l|l|}
\hline & ER & Factor VII & NA & TK \\
\hline Max Sim & 1 & 0.79 & 1 & 0.92 \\
\hline & & & & \\
\hline Mean Sim & 0.57 & 0.69 & 0.62 & 0.71 \\
\hline
\end{tabular}

Table 4: Similarities between the query used in the ROCS study and the actives for the INSERM study.

\section{The work of Pham}

\begin{tabular}{|l|l|l|l|l|}
\hline & OPPA & Trypsin & PARP & TS \\
\hline Max Sim & 1.0 & 1.0 & 1.0 & 1.0 \\
\hline & & & & \\
\hline Mean Sim & 0.88 & 0.51 & 0.59 & 0.60 \\
\hline
\end{tabular}

Table 5: Similarities between the query used in the ROCS study and the actives for the Pham study. Only systems not studied in the other experiments are recorded here. 